\title{
Marx e o processo de trabalho no final do século $\mathrm{XX}^{1}$
}

Benedito Rodrigues de Moraes Neto ${ }^{2}$

\section{Resumo:}

O artigo objetiva dissolver a identidade Taylor-Ford-Marx que prevaleceu na literatura sobre processo de trabalho no século XX. Recuperando de Marx a natureza autocontraditória do capital e a tendência crescente da “aplicação tecnológica da ciência”, avalia a automação de base microeletrônica como volta triunfal da questão crucial, para o autor alemão, da contradição entre forças produtivas e relações de produção, posta pelo desenvolvimento do modo de produção capitalista.

Palavras-chave: taylorismo; fordismo; Marx; processo de trabalho; microeletrônica.

\section{Marx and the labor process at the end of XX century}

\begin{abstract}
:
The objective of this paper is to dissolve an identity among Taylor-FordMarx which prevailed into labor process literature of XX century. Bringing back Marx's ideas about the self-contradictory nature of capital and the growing tendency of "technological application of science", one evaluates the microelectronic based automation as a triumphal return of a crucial question to that German thinker, that is, the contradiction between productive forces and relations of production placed by the development of the capitalist mode of production.
\end{abstract}

Key words: Taylorism; Fordism; Marx; labor process; microelectronics.

\footnotetext{
${ }^{1}$ Publicado originalmente como Nota sobre Marx e o processo de trabalho no final do século. Pesquisa \&Debate, São Paulo, v. 11, n. 2, 2000.

2 Livre-docente, professor aposentado da Universidade Estadual Paulista (UnespAraraquara). E-mail: brmneto@gmail.com.
} 


\section{1- Trabalho, progresso técnico e o enterro de Marx no final do século}

Na famosa tríade de capítulos de O capital - Cooperação, Manufatura e divisão do trabalho e Maquinaria e grande indústria - , Marx explicita sua visão sobre o movimento de ajuste das bases técnicas à forma social capitalista. Nesse movimento teórico, é fundamental a questão da desqualificação do trabalho ao longo do desenvolvimento tecnológico: no caminho da cooperação simples, com sua prisão à forma artesanal, até a maquinaria, passando pela manufatura, radicalizar-se-ia um movimento de desqualificação do trabalho, o que teria importantes desdobramentos em termos de controle do capital sobre a classe trabalhadora. A evolução dos processos de produção levaria, portanto, a uma homogeneização do trabalho simples, ou seja, do trabalho desprovido de conteúdo, momento fundamental do processo de alienação do homem relativamente ao trabalho, cujo conteúdo teria sido retirado como uma exigência da forma capitalista de dominação. Essa análise de Marx, que foi realizada sobre a experiência histórica do século XIX, avançaria ao longo do século XX. A força teórica de Marx se manifestaria na capacidade de incorporar em sua análise os movimentos mais importantes do processo de trabalho industrial do século XX, com destaque para o taylorismo e o fordismo.

O recurso a citações de autores bastante conhecidos vem em auxílio à ideia de que Marx teria sido um competente antecipador de um fenômeno típico do século XX, o taylorismo-fordismo. Isto seria muito caro aos marxistas na medida em que mostraria a profundidade da análise de Marx, ou seja, a sua capacidade de incorporar todos os movimentos que se verificariam ao longo do século XX. Iniciemos com Benjamin Coriat:

Tudo o que Marx anuncia em relação às características especificamente capitalistas do processo de trabalho (parcelamento de tarefas, incorporação do saber técnico no maquinismo, caráter despótico da direção), o realiza Taylor, ou mais exatamente, lhe dá uma extensão que até então não havia tido. (CORIAT, 1976, p. 107)

A noção de que o taylorismo significaria uma ilustração privilegiada da análise marxista do processo de trabalho tipicamente capitalista levou Robert Linhart a fazer uma afirmação extremamente relevante do ponto de vista teórico:

Numa análise do modo de produção capitalista "puro", a "organização científica do trabalho" de Taylor é a que se encontra melhor colocada para encarnar o processo de trabalho capitalista, reconduzido à sua essência. (LINHART, 1977, p. 89) 
Essa afirmação é bastante forte, pois implica que a essencialidade do processo de trabalho capitalista estaria incorporada à perfeição na proposta do taylorismo.

Um outro passo no processo de trazer Marx para o século XX tem que ver com o fordismo, com o fenômeno do taylorismo levado quase à perfeição por Henry Ford, nas suas tentativas - bem-sucedidas - de produção em massa do automóvel. O resultado das experimentações de Ford, a fábrica fordista, poderia ser chamada de "grande indústria por excelência do século XX". Isto se desdobra da consideração de que o taylorismo-fordismo possuiria uma conotação genérica: o processo de trabalho na grande indústria adquiriria, de maneira geral, uma natureza fordista, como corolário da própria produção em massa. Este processo de produção em grande escala através do recurso das linhas de montagem constrói, portanto, um conceito de grande indústria por excelência, como se tivéssemos então a concretização histórica da visão marxista da grande indústria. Construída a partir de um processo de desqualificação profunda do trabalho e empregadora de grande quantidade de trabalhadores, ela teria gerado o que Fergus Murray chamou de "mass-collective worker" (MURRAY, 1983). Essa grande indústria, que poderíamos chamar de "taylor-fordo-marxista", marcaria a própria natureza da produção capitalista: o capital exige o emprego de um elevadíssimo número de trabalhadores, justamente com o objetivo de extrair em grande volume a mais-valia. Esta característica genérica da produção industrial teria permitido também um desenvolvimento importante da luta capital $\mathrm{x}$ trabalho, na medida em que poderia levar ao fortalecimento da atividade sindical e, ao mesmo tempo, dos partidos ligados aos interesses da classe trabalhadora.

Chegamos, todavia, aos anos 1980 e ao seu revolucionamento tecnológico fundamental na esfera produtiva: a nova automação, de base microeletrônica. Esse revolucionamento dos processos de trabalho industrial significa uma "explosão" da grande indústria "taylor-fordomarxista", na direção da "unmanned factory", dotada de elevado grau de prescindibilidade do trabalho vivo imediatamente aplicado à produção. Se a revolução tecnológica das últimas décadas do século XX "explode" o paradigma taylorista-fordista, que ilustraria à perfeição todas as características apontadas por Marx para a natureza especificamente capitalista dos processos de trabalho, é totalmente coerente a afirmação de Augusto Marzagão, realizada em artigo no qual comenta o conhecido livro O horror econômico, de Viviane Forrester:

Na opinião de Viviane Forrester, passamos a viver um tempo em que o trabalho não tem mais quase nenhum poder de pressão sobre o capital, pois este precisa cada vez menos do trabalho humano. Os trabalhadores nem mesmo encontram 
interessados em explorá-los, vendo então ser virada pelo avesso a teoria marxista. (MARZAGÃO, 1997)

Ora, se a grande indústria taylor-fordista é também a grande indústria marxista, essa afirmação é, como já dissemos, totalmente coerente. Alguns desdobramentos dos movimentos de "explosão" da grande indústria taylor-fordo-marxista são extremamente importantes. Em primeiro lugar, temos o esgotamento da análise de Marx do processo de trabalho capitalista, fato comprometedor de toda sua obra teórica. Se o modo de produção capitalista continua, e a teoria marxista do processo de trabalho capitalista - que teria atingido seu ápice com a caracterização da grande indústria taylor-fordista - fenece, então a análise marxista do capitalismo não teria sido tão percuciente. Evidentemente, uma análise percuciente do modo de produção capitalista não pode prescindir desse momento teórico fundamental constituído pelo entendimento de suas bases técnicas, da natureza de seus processos produtivos.

O outro desdobramento, estreitamente amarrado ao primeiro, é constituído pelo surgimento de uma postura desesperançada e saudosista do fordismo por parte dos críticos do capitalismo. Em primeiro lugar, sobrevém a questão crucial do agente da transformação social. Ora, se a grande fábrica taylor-fordista representava a manifestação da visão marxista da grande indústria, então ela representaria também a "ponte" que levaria do capitalismo desenvolvido para o socialismo, a partir da ação política do "mass-collective worker". O progresso técnico "explodiu" esta ponte, levando a uma grande desesperança, à perda de referências fundamentais da transformação social.

A nosso juízo, o percurso teórico até aqui referido, que levou ao enterro de Marx, está amplamente equivocado. O próximo item deste texto é uma tentativa de refutação desse caminho e de sua substituição.

\section{2- Trabalho, progresso técnico e renascimento de Marx no final do século}

O lócus central da reflexão está no conceito de máquina que Marx constrói em O capital. A ideia fundamental é a de que Marx não é Adam Smith ${ }^{3}$. Adam Smith é o teórico por excelência da manufatura; portanto, a desqualificação do trabalho para ele implica incorporação "massiva" de trabalho simples, parcelado, desqualificado. Em Marx, o que se observa, com a introdução da máquina, é um processo de cientificização, de objetivação do processo de trabalho, que faz que este passe a ser uma

3 Esta é a ideia central do artigo Automação e trabalho: Marx igual a Adam Smith? (MORAES NETO, 1995). 
“aplicação tecnológica da ciência”. Essa noção fundamental de Marx implica que o trabalho vivo imediatamente aplicado à produção passa a ser "apendicizado", ou seja, amplamente desqualificado, na medida em que o processo de separação entre concepção e execução teria chegado a um auge, mas - e isto é muito importante - não só desqualificado, como já o era em grande medida na manufatura, mas fundamentalmente supérfluo. A ideia da superfluidade do trabalho vivo constitui uma contribuição fundamental de Marx para o estudo do processo de trabalho tipicamente capitalista. Observa-se, então, com o recurso da maquinaria, aquilo que Marx chamou de "superação da barreira orgânica", ou seja, uma superação radical do homem como instrumento de produção. A esse respeito, vale destacar uma frase muito feliz de Marx, quando afirma ser o homem "um instrumento muito imperfeito de produção quando se trata de conseguir movimentos uniformes e contínuos". Nos Grundrisse, Marx afirma que, a partir da constituição das bases técnicas especificamente capitalistas, o processo produtivo deixaria de ser um processo de trabalho, no sentido de que o trabalho deixaria de ser a unidade dominante.

É a partir dessa reflexão que Marx introduz algo fundamental do ponto de vista de sua contribuição teórica: a ideia da natureza autocontraditória do capital. Em poucas palavras, ao encetar esse desenvolvimento das forças produtivas, o capital agiria contra seus interesses - em termos de forma social - no mais longo prazo. É sabido que Marx considera o capitalismo um modo de produção brilhante no que diz respeito ao desenvolvimento das forças produtivas, mas ao mesmo tempo o considera medíocre enquanto forma social. Uma forma social que se lastreia na exploração do trabalho é imanentemente medíocre. O movimento de desenvolvimento das forças produtivas significa para Marx uma "trombada" futura das potencialidades abertas por esse desenvolvimento com as barreiras postas pela forma social. A proeminência do trabalho morto, ou seja, dos elementos objetivos do processo de trabalho, a objetivação crescente, traria não só desdobramentos importantes de natureza econômica, mas uma perda de sentido histórico da forma capitalista: uma forma social que se alicerça na exploração do homem pelo homem deixa de ter sentido histórico se o processo produtivo deixa de usar o próprio homem.

A partir dessa correta compreensão conceitual da maquinaria, a entrada em cena no século XX do taylorismo-fordismo é, sem dúvida, causadora de perplexidade. Quem estuda o taylorismo observa que, no fundo, o que Taylor tenta fazer é transformar novamente o homem num instrumento de produção, analogamente ao que se havia tentado na fase pré-maquinaria. Essa visão do homem como instrumento de produção magnifica-se no fordismo. Ao encetar sua típica inovação, que é a linha de 
montagem, Ford não fez outra coisa senão coletivizar o taylorismo, com o recurso fundamental da esteira, que procura resolver o problema tipicamente manufatureiro do transporte. Na verdade, esta grande fábrica fordista, ao invés de significar a indústria por excelência, a forma mais avançada da produção capitalista, significou, isto sim, uma "reinvenção da manufatura", uma coisa extremamente atrasada do ponto de vista conceitual, a despeito de seu imenso sucesso do ponto de vista econômico, produtivo ${ }^{4}$. A colocação de milhares de trabalhadores, uns ao lado dos outros, fazendo movimentos parciais, de forma alguma ajusta-se à noção marxista de produção à base de maquinaria. Por isso afirmamos acima: Marx não é Adam Smith. A grande indústria fordista não significa, portanto, uma ilustração do conceito marxista de grande indústria; na verdade, significa sua negação.

Vale destacar que, embora amplamente disseminado, é equivocado considerar a forma de produção fordista genérica, capaz de dar conta de uma maneira geral da atividade industrial capitalista ao longo do século XX. Ela é extremamente importante, mas não é generalizável; não se pode estendêla, por exemplo, para os casos das indústrias têxtil e de fluxo contínuo, que há muito tempo se ajustaram à produção automatizada 5 . $\mathrm{O}$ caminho do taylorismo-fordismo significa na verdade um "desvio mediocrizante" do capitalismo no que se refere ao desenvolvimento das forças produtivas, amplamente vinculado à indústria metal-mecânica. Afinal, não é nada brilhante colocar o ser humano em atividades sem conteúdo e medir seus tempos e movimentos como um instrumento de produção, assim como não é nada brilhante colocar milhares de pessoas, umas ao lado das outras, fazendo movimentos repetitivos. Isto não tem nada que ver com a utilização da ciência como força produtiva, não fazjus à colocação de Marx do brilhantismo do capitalismo quanto ao desenvolvimento das forças produtivas. Esse "desvio mediocrizante" do capitalismo significou uma harmonização preocupante entre a mediocridade das forças produtivas e a mediocridade da forma social. Se é assim, será que a grande indústria taylor-fordista (não mais taylor-fordomarxista, mas apenas taylor-fordista) merecia ter sido vista como a "ponte" que poderia levar do capitalismo desenvolvido para o socialismo?

Como já vimos, a nova automação, de base microeletrônica, "explode" esta forma de produção, não genérica, mas localizada principalmente na grande indústria metal-mecânica, fundamental em todo o processo de acumulação de capital ao longo do século XX. Essa nova

\footnotetext{
4 Esta ideia acha-se desenvolvida em Marx, Taylor, Ford: as forças produtivas em discussão (MORAES NETO, 1989).

5 Este ponto está desenvolvido em Fordismo e ohnoísmo: trabalho e tecnologia na produção em massa (MORAES NETO, 1998) e também está presente, ainda que de forma pontual, em Williams; Cutler; Williams; e Haslam (1987).
} 
automação significa uma abrupta, concentrada no tempo, recuperação do capital de seu brilhantismo quanto ao desenvolvimento das forças produtivas. Portanto, ao invés de dizer, como Augusto Marzagão, que a "explosão" da grande indústria taylor-fordista significa o enterro da análise marxista, devemos, pelo contrário, considerá-la o renascimento da análise marxista. Isto porque chegaremos, de forma genérica, homogênea a toda atividade industrial, a um elevadíssimo grau de cientificização dos processos produtivos. A produção será, então, em todas as esferas da indústria, uma "aplicação tecnológica da ciência", exatamente como afirmara Marx. Isto implica a volta triunfal da questão crucial para Marx da contradição entre forças produtivas e relações de produção, posta pelo desenvolvimento do modo de produção capitalista. Essa "capacidade" do capital de se mover de maneira autocontraditória é negada pelo taylorismo-fordismo. Este nega a contradição entre forças produtivas e relações de produção. A constituição de "macrofábricas", empregando milhares de trabalhadores parciais, desqualificados, seria a forma de o capital se eternizar, seria a eternização da forma social capitalista, pois a função social do capitalista estaria preservada. O contrário ocorre quando o capital "explode" a base taylor-fordista e avança pelo seu caminho inexorável de desenvolvimento das forças produtivas, pois aí ele caminha no sentido da negação da sua natureza.

\section{Referências bibliográficas}

CORIAT, Benjamin. Ciencia, tecnica y capital. Madri: H. Blume Ediciones, 1976.

FORRESTER, Viviane. O horror econômico. São Paulo: Ed. Unesp, 1997.

LINHART, Robert. Lenine, os camponeses e Taylor. Lisboa: Iniciativas Editoriais, 1977.

MARX, Karl. Elementos fundamentales para la crítica de la economía política (Grundrisse), 1857-1858. 7. ed. México: Siglo Veintiuno, 1978. . O capital. São Paulo: Abril Cultural, 1983.

MARZAGÃO, Augusto. O horror dos excluídos. Folha de S. Paulo, 4 set. 1997.

MORAES NETO, B. R. Marx, Taylor, Ford: as forças produtivas em discussão. São Paulo: Brasiliense, 1989.

. Automação e trabalho: Marx igual a Adam Smith? Estudos Econômicos, IPE-FEA/USP, jan. -abr. 1995.

. Fordismo e ohnoísmo: trabalho e tecnologia na produção em massa. Estudos Econômicos, IPE-FEA/USP, v. 28, n. 2, 1998.

MURRAY, Fergus. The decentralisation of production - the decline of the mass-collective worker? Capital \& Class, Londres, n. 19, pp. 74-99, 1983. 
WILLIAMS, K.; CUTLER, T.; WILLIAMS, J.; HASLAM, C. The end of mass production? Economy and Society, v. 16, n. 13, 1987.

Como citar:

MORAES NETO, Benedito Rodrigues de. Marx e o processo de trabalho no final do século. Verinotio - Revista on-line de Filosofia e Ciências Humanas, Rio das Ostras, v. 24, n. 2, pp. 46-53, nov. 2018.

Data de envio: 20 jun. 2018

Data de aceite: 11 set. 2018 